\title{
Reliability and Validity of the Alcohol Use Disorders Identification Test - Consumption in Screening for Adults with Alcohol Use Disorders and Risky Drinking In Japan
}

\author{
Yoneatsu Osaki ${ }^{1 *}$, Aro Ino ${ }^{2}$, Sachio Matsushita ${ }^{3}$, Susumu Higuchi $^{3}$, Yoko Kondo ${ }^{1}$, \\ Aya Kinjo ${ }^{1}$
}

\begin{abstract}
Background: Alcohol is well established as a risk factor for cancer development in many organ sites. To assess the reliability and validity of the Alcohol Use Disorders Identification Test - Consumption (AUDIT-C) for detecting alcohol use disorders or risky drinking in Japanese adults the present study was conducted. Materials and Methods: A test-retest method was applied with a 2-week interval with 113 health care employees. The $\kappa$ coefficient, Cronbach's coefficient alpha, Spearman's correlation coefficient, and intraclass correlation coefficient (ICC) were determined and the validity of the AUDIT-C was analyzed using the data from a nationwide survey on adult alcohol use conducted in $2008(n=4,123)$. Results: The reliability of the AUDIT-C score was high $(\kappa$ coefficient $=0.63$, Cronbach's alpha $=0.98$, correlation coefficient $=0.95$, and $\mathrm{ICC}=0.95$ ). According to the likelihood ratio and Youden index, appropriate cutoffs for the AUDIT-C were $\geq 5$ points in men and $\geq 4$ points in women. The sensitivity and specificity of these cutoffs for identifying $\geq 8$ points on the AUDIT were 0.88 and 0.80 , respectively, for men (positive likelihood ratio $[L R+]=4.5)$ and 0.96 and 0.87 , respectively, for women $(L R+=7.7)$. The sensitivity and specificity of the cutoffs for identifying $\geq 12$ points on the AUDIT were 0.90 and 0.84 , respectively, for men $(L R+=5.8)$ and 0.93 and 0.94 , respectively, for women $(L R+=15.8)$. The sensitivity and specificity of the cutoffs for identifying $\geq 16$ points on the AUDIT were 0.93 and 0.80 , respectively, for men $(L R+=4.7)$ and 0.92 and 0.98 , respectively, for women (LR+=55.6). With higher scores on the AUDIT, the specificity decreased and false-positives increased. The appropriate cutoffs for identifying risky drinking were the same for both genders. Conclusions: The reliability and validity of the AUDIT-C are high, indicating that it is useful for identifying alcohol use disorders or risky drinking among the general population in Japan, a group at high risk of cancer development.
\end{abstract}

Keywords: AUDIT-C - alcohol use disorders - alcohol use disorders identification test - screening - risk drinking

Asian Pac J Cancer Prev, 15 (16), 6571-6574

\section{Introduction}

Excessive alcohol consumption is associated with not only multiple health problems including cancer but also many social problems such as drunken driving, child abuse, and domestic violence; it also leads to substantial social expense (WHO, 2009; Osaki et al., 2012; de Menezes et al., 2013; Yaegashi et al., 2014). Screening tests have been proposed to identify alcohol use disorders. The Alcohol Use Disorders Identification Test (AUDIT) is one of the popular screening tests used in Western countries, and an intervention program based on the results of this test has been introduced (Babor et al., 2001).

The test consists of 10 questions, and each response for the questions is assigned a specific score. The total AUDIT score is calculated by adding up the scores from all of the questions. Based on the AUDIT score, respondents are classified into categories of alcohol use disorders (Babor et al., 2001).

The AUDIT was developed as a self-reported tool; however, in general health care settings, a substantial amount of time may be required to respond to all of the questions. Owing to the attention placed on social problems relating to alcohol use disorders globally, the Japanese government has recently started to address alcohol problems. In Japan, a brief intervention to reduce alcohol consumption in people with an alcohol use disorder at clinics or during health examinations has been expected in recent years. Therefore, a short screening test is required by busy medical facilities in Japan. 
The AUDIT Consumption (AUDIT-C) includes the first 3 questions of the AUDIT and is proposed and used in Western countries. The reliability and validity of the AUDIT-C have been determined for use in Western countries. To detect problem drinking, the proposed cutoffs for the AUDIT-C are $\geq 5$ points for men and $\geq 3$ points for women (Johnson et al, 2013). The present study aimed to assess the reliability and validity of the AUDIT-C for detecting suspected alcohol dependence, alcohol use disorders, or risky drinking in Japanese adults. To the best of our knowledge, this study is the first conducted in an Asian country to assess the reliability and validity of the AUDIT-C.

\section{Materials and Methods}

\section{Assessment of the reliability of the AUDIT-C}

The reliability of the AUDIT-C was assessed using a test-retest method to determine its reproducibility. The subjects were 113 employees working in psychiatry medical clinics $(n=27)$, a nursing facility $(n=51)$, a rehabilitation facility $(\mathrm{n}=21)$, and a health examination organization $(n=14)$ in Mie Prefecture, Japan. We asked the subjects to complete the AUDIT-C twice with 2 weeks between the 2 tests. The survey was conducted in October 2011.

\section{Assessment of the validity of the AUDIT-C}

We assessed the validity of the AUDIT-C using data from a nationwide survey on adult drinking behaviors in Japan conducted in 2008. The nationwide survey was interview-based and conducted in the subjects' homes; subjects were selected randomly from resident register lists of the municipalities. Of the selected 6,956 subjects, 4,123 people responded to the survey (response rate $=59.3 \%$ ). Trained interviewers visited the subjects' houses and asked them to participate in the survey.

The questionnaire included the full AUDIT in addition to questions about alcohol use behaviors including the frequency of alcohol use, average alcohol consumption on a day that included drinking, and the frequency of binge drinking (pure alcohol consumption $\geq 60$ g per drinking occasion).

Ethical approval was provided by the ethical committees of the Faculty of Medicine of Tottori University and the Kurihama Medical and Alcohol Center.

\section{Statistical analyses}

To determine the reliability, we calculated the $\kappa$ coefficient, Cronbach's coefficient alpha, Spearman's correlation coefficient, and intraclass correlation coefficient (ICC).

The validity was assessed by comparing the total score of the full AUDIT, which was considered the gold standard, with the AUDIT-C score. We calculated the sensitivity and specificity. We also determined appropriate cutoffs for the AUDIT-C in the Japanese population using the positive likelihood ratio and Youden index (Youden, 1950; Akobeng, 2007). Youden index is defined as "sensitivity+specificity - 1".

We also assessed the effectiveness of the AUDIT-C

for identifying risky drinking. Risky drinking was defined as heavy drinking ( $280 \mathrm{~g}$ pure alcohol/week for men and $168 \mathrm{~g}$ pure alcohol/week for women) or binge drinking (consumption of $60 \mathrm{~g}$ pure alcohol on $\geq 1$ occasion per week). Statistical analyses were conducted using SPSS for Windows ver. 18 (SPSS Inc., Chicago, IL, USA).

\section{Results}

\section{Assessment of reliability}

The total AUDIT-C score and scores for each AUDIT-C question demonstrated a high level of agreement between the repeated surveys (Table 1). Each index of agreement was close to 1 . Therefore, we observed a high reproducibility of the AUDIT-C. However, the reproducibility of questions 2 and 3 of the AUDIT-C was relatively low compared to that of question 1 (Table 1).

\section{Assessment of validity}

The Spearman's correlation coefficient for the relationship between each question and the total score of the full AUDIT was 0.93 for question 1, 0.61 for question 2, and 0.67 for question 3. Table 2 provides the sensitivity, specificity, positive likelihood ratio, and Youden index of the AUDIT-C categorized by cutoff values of the full AUDIT score ( $\geq 8$ points, $\geq 12$ points, $\geq 16$ points, and $\geq 20$ points). The AUDIT-C cutoffs are $\geq 5$ points for men and $\geq 3$ points for women when the tool is used in Western countries. The sensitivity and specificity of these cutoffs for an AUDIT score $\geq 8$ points were $88 \%$ and $80 \%$, respectively, for men and $98 \%$ and $78 \%$, respectively, for women. The sensitivity and specificity of the same cutoffs for an AUDIT score $\geq 12$ points were $96 \%$ and $72 \%$, respectively, for men and $96 \%$ and $76 \%$, respectively, for women. The sensitivity and specificity of the same cutoffs for an AUDIT score $\geq 16$ points were $100 \%$ and $66 \%$, respectively, for men and $83 \%$ and $76 \%$, respectively, for women.

A decrease in the positive likelihood ratio was observed with a higher AUDIT score, which indicates a more serious drinking problem. When the cutoffs used in Western countries were applied, the specificity was relatively low, and a trend for increased false positives was observed. According to the Youden index, the appropriate cutoffs for the AUDIT-C were $\geq 5$ points for men and $\geq 4$ points for women in this Japanese sample. Table 3 provides the sensitivity, specificity, positive likelihood ratio, and Youden index for identifying risky drinking. The same appropriate cutoffs were observed for identifying heavy drinking or binge drinking. However, the AUDIT-C demonstrated high sensitivity and specificity in women

Table 1. Reliability of the Alcohol Use Disorders Identification Test - Consumption (AUDIT-C)

\begin{tabular}{lllccc}
\hline Items & $\kappa$ & $\alpha$ & $\begin{array}{c}\text { Spearman's } \\
\text { coefficient of } \\
\text { correlation }\end{array}$ \\
\hline AUDIT-1 & 0.866 & 0.985 & 0.971 & 0.971 & $(0.958-0.980)$ \\
AUDIT-2 & - & 0.907 & 0.833 & 0.831 & $(0.765-0.881)$ \\
AUDIT-3 & - & 0.909 & 0.836 & 0.831 & $(0.764-0.880)$ \\
AUDIT-C score & 0.628 & 0.975 & 0.952 & 0.951 & $(0.930-0.966)$ \\
\hline
\end{tabular}


Table 2. Validity of the Alcohol Use Disorders Identification Test - Consumption (AUDIT-C) for Identifying Alcohol Use Disorders Categorized by AUDIT Cut-offs

\begin{tabular}{|c|c|c|c|c|c|c|c|c|c|c|c|c|c|c|c|c|c|c|c|c|}
\hline & \multicolumn{5}{|c|}{ AUDIT $\geq 8$ points } & \multicolumn{5}{|c|}{ AUDIT $\geq 12$ points } & \multicolumn{5}{|c|}{ AUDIT $\geq 16$ points } & \multicolumn{5}{|c|}{ AUDIT $\geq 20$ points } \\
\hline & $\mathrm{Se}$ & $\mathrm{Sp}$ & PPV & LR+ & $\begin{array}{l}\text { Youden } \\
\text { Index }\end{array}$ & $\mathrm{Se}$ & $S p$ & PPV & LR+ & $\begin{array}{l}\text { Youden } \\
\text { Index }\end{array}$ & $\mathrm{Se}$ & $\mathrm{Sp}$ & PPV & LR+ & $\begin{array}{l}\text { Youden } \\
\text { Index }\end{array}$ & $\mathrm{Se}$ & $\mathrm{Sp}$ & PPV & LR+ & $\begin{array}{c}\text { Youden } \\
\text { Index }\end{array}$ \\
\hline \multicolumn{21}{|c|}{ AUDIT-C cutoffs } \\
\hline \multicolumn{21}{|c|}{ Men } \\
\hline$\geq 1$ point & 1.00 & 0.28 & 0.30 & 1.39 & 0.28 & 1.00 & 0.24 & 0.14 & 1.32 & 0.24 & 0.99 & 0.23 & 0.06 & 1.28 & 0.22 & 1.00 & 0.22 & 0.03 & 1.29 & 0.22 \\
\hline$\geq 2$ points & 1.00 & 0.39 & 0.33 & 1.63 & 0.39 & 1.00 & 0.33 & 0.15 & 1.49 & 0.33 & 0.99 & 0.31 & 0.07 & 1.44 & 0.30 & 1.00 & 0.30 & 0.03 & 1.44 & 0.30 \\
\hline$\geq 3$ points & 1.00 & 0.48 & 0.37 & 1.93 & 0.48 & 1.00 & 0.42 & 0.17 & 1.70 & 0.41 & 0.99 & 0.39 & 0.08 & 1.62 & 0.38 & 1.00 & 0.38 & 0.03 & 1.61 & 0.38 \\
\hline$\geq 4$ points & 0.98 & 0.61 & 0.44 & 2.51 & 0.59 & 0.99 & 0.53 & 0.20 & 2.09 & 0.52 & 0.98 & 0.49 & 0.09 & 1.93 & 0.47 & 1.00 & 0.48 & 0.04 & 1.92 & 0.48 \\
\hline$\geq 5$ points & 0.88 & 0.80 & 0.58 & 4.51 & 0.69 & 0.96 & 0.72 & 0.29 & 3.38 & 0.68 & 0.97 & 0.67 & 0.13 & 2.96 & 0.64 & 1.00 & 0.66 & 0.06 & 2.90 & 0.66 \\
\hline$\geq 6$ points & 0.75 & 0.92 & 0.74 & 9.42 & 0.67 & 0.90 & 0.84 & 0.41 & 5.81 & 0.75 & 0.93 & 0.80 & 0.19 & 4.65 & 0.73 & 0.95 & 0.78 & 0.08 & 4.28 & 0.73 \\
\hline$\geq 7$ points & 0.56 & 0.98 & 0.90 & 27.93 & 0.54 & 0.75 & 0.93 & 0.55 & 10.20 & 0.68 & 0.82 & 0.89 & 0.27 & 7.26 & 0.71 & 0.92 & 0.87 & 0.13 & 6.98 & 0.79 \\
\hline$\geq 8$ points & 0.36 & 1.00 & 1.00 & $\infty$ & 0.36 & 0.56 & 0.97 & 0.72 & 20.81 & 0.53 & 0.67 & 0.95 & 0.38 & 12.24 & 0.62 & 0.79 & 0.93 & 0.19 & 11.27 & 0.72 \\
\hline$\geq 9$ points & 0.22 & 1.00 & 1.00 & $\infty$ & 0.22 & 0.41 & 0.99 & 0.86 & 48.71 & 0.40 & 0.53 & 0.97 & 0.49 & 19.26 & 0.50 & 0.63 & 0.96 & 0.25 & 15.94 & 0.59 \\
\hline$\geq 10$ points & 0.12 & 1.00 & 1.00 & $\infty$ & 0.12 & 0.25 & 1.00 & 0.93 & 102.70 & 0.24 & 0.37 & 0.99 & 0.63 & 33.42 & 0.36 & 0.50 & 0.98 & 0.35 & 26.31 & 0.48 \\
\hline$\geq 11$ points & 0.05 & 1.00 & 1.00 & $\infty$ & 0.05 & 0.10 & 1.00 & 0.95 & 164.31 & 0.10 & 0.15 & 1.00 & 0.67 & 39.32 & 0.15 & 0.13 & 0.99 & 0.24 & 15.15 & 0.12 \\
\hline \multicolumn{21}{|c|}{ Area under the ROC curve (S.E.) } \\
\hline & 0.932 & $(0.00$ & & & & 0.939 & $(0.008$ & & & & 0.930 & (0.014 & & & & 0.949 & (0.011 & & & \\
\hline \multicolumn{21}{|l|}{ Women } \\
\hline$\geq 1$ point & 1.00 & 0.48 & 0.07 & 1.91 & 0.48 & 1.00 & 0.46 & 0.02 & 1.87 & 0.46 & 1.00 & 0.46 & 0.01 & 1.86 & 0.46 & 1.00 & 0.46 & 0.00 & 1.85 & 0.46 \\
\hline$\geq 2$ points & 0.99 & 0.65 & 0.10 & 2.84 & 0.64 & 0.96 & 0.64 & 0.03 & 2.64 & 0.60 & 0.92 & 0.63 & 0.01 & 2.50 & 0.55 & 0.83 & 0.63 & 0.01 & 2.25 & 0.46 \\
\hline$\geq 3$ points & 0.98 & 0.78 & 0.15 & 4.52 & 0.76 & 0.96 & 0.76 & 0.05 & 4.10 & 0.73 & 0.92 & 0.76 & 0.02 & 3.84 & 0.68 & 0.83 & 0.76 & 0.01 & 3.43 & 0.59 \\
\hline$\geq 4$ points & 0.96 & 0.87 & 0.23 & 7.68 & 0.84 & 0.96 & 0.85 & 0.08 & 6.57 & 0.82 & 0.92 & 0.85 & 0.03 & 6.05 & 0.77 & 0.83 & 0.84 & 0.01 & 5.37 & 0.68 \\
\hline$\geq 5$ points & 0.86 & 0.96 & 0.46 & 22.03 & 0.82 & 0.93 & 0.94 & 0.17 & 15.82 & 0.87 & 0.92 & 0.94 & 0.08 & 14.29 & 0.86 & 0.83 & 0.93 & 0.03 & 12.35 & 0.77 \\
\hline$\geq 6$ points & 0.69 & 0.99 & 0.64 & 46.59 & 0.68 & 0.82 & 0.97 & 0.26 & 27.16 & 0.79 & 0.92 & 0.97 & 0.13 & 26.39 & 0.89 & 0.83 & 0.96 & 0.06 & 21.93 & 0.80 \\
\hline$\geq 7$ points & 0.46 & 1.00 & 0.80 & 100.24 & 0.46 & 0.75 & 0.99 & 0.43 & 59.33 & 0.74 & 0.92 & 0.98 & 0.24 & 55.63 & 0.91 & 0.83 & 0.98 & 0.10 & 42.37 & 0.81 \\
\hline$\geq 8$ points & 0.37 & 1.00 & 1.00 & $\infty$ & 0.37 & 0.68 & 0.99 & 0.61 & 125.25 & 0.67 & 0.85 & 0.99 & 0.35 & 94.35 & 0.84 & 0.83 & 0.99 & 0.16 & 71.70 & 0.82 \\
\hline$\geq 9$ points & 0.21 & 1.00 & 1.00 & $\infty$ & 0.21 & 0.50 & 1.00 & 0.78 & 276.88 & 0.50 & 0.62 & 1.00 & 0.44 & 137.23 & 0.61 & 0.67 & 0.99 & 0.221 & 106.52 & 0.66 \\
\hline$\geq 10$ points & 0.10 & 1.00 & 1.00 & $\infty$ & 0.10 & 0.29 & 1.00 & 1.00 & $\infty$ & 0.29 & 0.31 & 1.00 & 0.50 & 171.54 & 0.31 & 0.50 & 1.00 & 0.382 & 223.70 & 0.50 \\
\hline$\geq 11$ points & 0.08 & 1.00 & 1.00 & $\infty$ & 0.08 & 0.25 & 1.00 & 1.00 & $\infty$ & 0.25 & 0.31 & 1.00 & 0.57 & 228.72 & 0.31 & 0.50 & 1.00 & 0.432 & 279.63 & 0.50 \\
\hline \multicolumn{21}{|c|}{ Area under the ROC curve (S.E.) } \\
\hline & \multicolumn{5}{|c|}{$0.974(0.007)$} & \multicolumn{5}{|c|}{$0.972(0.016)$} & \multicolumn{5}{|c|}{$0.961(0.034)$} & \multicolumn{5}{|c|}{$0.921(0.069)$} \\
\hline
\end{tabular}

*AUDIT-C: Alcohol Use Disorders I

characteristics; S.E.: standard error

Table 3. Validity of the Alcohol Use Disorders Identification Test - Consumption (AUDIT-C) for Identifying Heavy Drinking and Binge Drinking

\begin{tabular}{|c|c|c|c|c|c|c|c|c|c|c|}
\hline & & $\begin{array}{r}\mathrm{He} \\
/ \mathrm{F}^{*} \geq\end{array}$ & $\begin{array}{l}\text { avy d } \\
280 / \geq\end{array}$ & $\begin{array}{l}\text { rinkin } \\
168 \mathrm{~g}\end{array}$ & $\begin{array}{l}\text { g } \\
\text { /week) }\end{array}$ & $(\geq 60$ & $\begin{array}{l}\text { Bin } \\
\text { g eth }\end{array}$ & $\begin{array}{l}\text { ge dri } \\
\text { anol } \geq\end{array}$ & $\begin{array}{l}\text { nking } \\
1 \text { time/ }\end{array}$ & (week) \\
\hline & $\mathrm{Se}$ & $\mathrm{Sp}$ & PPV & LR+ & Youden & $\mathrm{Se}$ & Sp & PPV & & Youden \\
\hline & & & & & Index & & & & & Index \\
\hline AUDIT-C cu & utoffs & & & & & & & & & \\
\hline Men & & & & & & & & & & \\
\hline$\geq 1$ point & 0.99 & 0.26 & 0.19 & 1.33 & 0.24 & 0.99 & 0.24 & 0.11 & 1.29 & 0.22 \\
\hline$\geq 2$ points & 0.99 & 0.35 & 0.22 & 1.52 & 0.34 & 0.99 & 0.33 & 0.12 & 1.46 & 0.31 \\
\hline$\geq 3$ points & 0.99 & 0.44 & 0.24 & 1.75 & 0.42 & 0.97 & 0.40 & 0.13 & 1.62 & 0.37 \\
\hline$\geq 4$ points & 0.99 & 0.55 & 0.29 & 2.20 & 0.54 & 0.95 & 0.51 & 0.15 & 1.94 & 0.46 \\
\hline$\geq 5$ points & 0.89 & 0.74 & 0.38 & 3.37 & 0.62 & 0.85 & 0.69 & 0.20 & 2.73 & 0.54 \\
\hline$\geq 6$ points & 0.70 & 0.85 & 0.45 & 4.57 & 0.55 & 0.72 & 0.81 & & 3.78 & 0.53 \\
\hline$\geq 7$ points & 0.53 & 0.92 & 0.55 & 6.67 & 0.45 & 0.58 & 0.89 & 0 & 5.37 & 0.47 \\
\hline$\geq 8$ points & 0.36 & 0.97 & 0.65 & 10.45 & 0.33 & 0.45 & 0.95 & 0.45 & 8.84 & 0.40 \\
\hline$\geq 9$ points & 0.24 & 0.98 & 0.71 & 13.62 & 0.22 & 0.35 & 0.98 & 0.59 & 15.21 & 0.33 \\
\hline$\geq 10$ points & s 0.15 & 0.99 & 0.78 & 19.35 & 0.14 & 0.25 & 0.99 & 0.76 & 33.67 & 0.25 \\
\hline$\geq 11$ points & 0.06 & 1.00 & 0.86 & 33.17 & 0.06 & 0.09 & 1.00 & 0.67 & 21.35 & 0.08 \\
\hline Area under th & the $\mathrm{RC}$ & DC cur & rve (S. & & & & & & & \\
\hline & 0.88 & )$(0.01$ & & & & & 0.857 & $(0.015$ & & \\
\hline Women & & & & & & & & & & \\
\hline$\geq 1$ point & 0.97 & 0.47 & 0.06 & 1.85 & 0.45 & 1.00 & 0.46 & 0.03 & 1.87 & 0.46 \\
\hline$\geq 2$ points & 0.96 & 0.65 & 0.09 & 2.74 & 0.61 & 1.00 & 0.64 & 0.04 & 2.75 & 0.64 \\
\hline$\geq 3$ points & 0.95 & 0.78 & 0.14 & 4.34 & 0.73 & 0.94 & 0.77 & 0.05 & 3.99 & 0.70 \\
\hline$\geq 4$ points & 0.91 & 0.87 & 0.20 & 7.04 & 0.78 & 0.90 & 0.85 & 0.08 & 6.17 & 0.76 \\
\hline$\geq 5$ points & 0.62 & 0.95 & 0.31 & 12.54 & 0.57 & 0.71 & 0.94 & 0.14 & 11.71 & 0.65 \\
\hline$\geq 6$ points & 0.47 & 0.98 & 0.41 & 19.12 & 0.44 & 0.68 & 0.97 & 0.23 & 21.72 & 0.65 \\
\hline$\geq 7$ points & 0.29 & 0.99 & 0.47 & 24.23 & 0.28 & 0.58 & 0.99 & 0.37 & 41.43 & 0.57 \\
\hline$\geq 8$ points & 0.23 & 0.99 & 0.58 & 37.93 & 0.22 & 0.45 & 0.99 & 0.45 & 58.76 & 0.44 \\
\hline$\geq 9$ points & 0.15 & 1.00 & 0.67 & 54.78 & 0.15 & 0.29 & 1.00 & 0.50 & 71.35 & 0.29 \\
\hline$\geq 10$ points & s 0.08 & 1.00 & 0.75 & 82.18 & 0.08 & 0.13 & 1.00 & 0.50 & 71.35 & 0.13 \\
\hline$\geq 11$ points & 0.06 & 1.00 & 0.71 & 68.48 & 0.06 & 0.13 & 1.00 & 0.57 & 95.14 & 0.13 \\
\hline Area under th & the $\mathrm{RC}$ & DC cur & Irve (S. & & & & & & & \\
\hline & 0.92 & $9(0.0$ & & & & & 0.948 & 0.0 & & \\
\hline
\end{tabular}

*M/F: Male/Female; **AUDIT-C: Alcohol Use Disorders Identification Test - Consumption; Se: sensitivity; Sp: specificity; PPV: positive predictive value; LR: positive likelihood ratio; ROC: receiver operating characteristics; S.E.: standard error

for identifying high AUDIT scores and risky drinking, compared with men. The specificity of the AUDIT-C for identifying risky drinking was relatively low in men.

\section{Discussion}

To the best of our knowledge, this is the first study to determine the reliability and validity of the AUDIT-C in an Asian country. The high reproducibility of the AUDIT-C was confirmed in the present study. The validity of the AUDIT-C was also high in this Japanese sample. It has been reported that there are many people with alcohol dependence in Japan (Osaki et al., 2005). However, only a portion of these people see doctors according to the relatively low estimate of patients that visit medical facilities reported in a national patient survey (Osaki, 2013). However, the general belief is that the majority of patients with alcohol use disorders visit medical facilities or undergo health examinations because of prevalent physical and mental problems. With appropriate screening by physicians, brief interventions can be implemented with patients at risk of alcohol use disorders, resulting in reduced alcohol consumption. The availability of a simple screening test in busy clinics or health examination settings would enable brief intervention programs aimed at reducing alcohol consumption to be implemented with patients with suspected alcohol use disorders. The high reliability and validity of the AUDIT-C indicate its potential effectiveness, as a proxy questionnaire for the full AUDIT, for identifying alcohol dependence in the general population in Japan.

Furthermore, the AUDIT-C is also considered to be an effective screening test for identifying risky drinkers, owing to the observed reliability and validity of the AUDIT-C for identifying heavy drinking or binge drinking. The appropriate AUDIT-C cutoffs for identifying heavy drinking or binge drinking were the same as those 
for identifying alcohol use disorders with the full AUDIT. The statistical analyses in the present study resulted in appropriate AUDIT-C cutoffs of $\geq 5$ points for men and $\geq 4$ points for women in Japan.

The cutoffs recommended for use in Western countries vary; however, the most commonly used cutoffs have been 4-6 points for men and 3-5 points for women (Bush et al., 1998; Nordqvist et al., 2004; Dawson et al., 2005; Gómez et al., 2006; Bradley et al., 2007; RodriguezMartos and Santamarina, 2007; Tuunanen et al., 2007; Frank et al., 2008; Kelly et al., 2009; Kaarne et al., 2010; Towers et al., 2011; Dawson et al., 2012; Crawford et al., 2013; Johnson et al., 2013). According to results from the United States and European countries, the AUDIT-C is a satisfactory screening tool for identifying alcohol dependence diagnosed by DSM-IV as binge drinking or heavy drinking with high sensitivity and specificity. One article indicated that the sensitivity of the AUDIT-C varies by race or ethnicity (Frank et al., 2008). The sensitivity and specificity of the AUDIT-C tend to be lower for specific populations, such as veterans or young patients in emergency services (Kelly et al., 2009; Crawford et al., 2013).

The results of the present study were similar to previous results. The sensitivity and specificity of the AUDIT-C for heavy drinking, binge drinking and the total AUDIT score in this Japanese sample were adequate compared to results from Western countries. Therefore, we could conclude that the use of the AUDIT-C as a screening test instead of the full AUDIT is appropriate in the Japanese population. The AUDIT-C can be used in primary health care and health examination settings to promote countermeasures for reducing alcohol-related disease burden and social problems in Japan. This indicates that AUDIT-C will be an useful tool for cancer prevention in Japan.

\section{Acknowledgements}

The research was funded by grants from the Ministry of Health Labour and Welfare, Japan (Health Labour Sciences Research Grant, \#H25-Junkanki-Seishugeneral-001).

\section{References}

Akobeng AK (2007). Understanding diagnostic tests 3: receiver operating characteristic curves. Acta Paediatr, 96, 644-7.

Babor TF, Higgins-Biddle JC, Saunders JB, Monteiro MG, World health organization dept of mental health and substance dependence (2001). audit: the alcohol use disorders identification test: guidelines for use in primary health care. 2nd ed. World Health Organization, Geneva.

Bradley KA, DeBenedetti AF, Volk RJ, et al (2007). AUDIT-C as a brief screen for alcohol misuse in primary care. Alcohol Clin Exp Res, 31, 1208-17.

Bush K, Kivlahan DR, McDonell MB, Fihn SD, Bradley KA (1998). The AUDIT alcohol consumption questions (AUDIT-C): an effective brief screening test for problem drinking. ambulatory care quality improvement project (ACQUIP). Alcohol Use Disorders Identification Test. Arch Intern Med, 158, 1789-95.

Crawford EF, Fulton JJ, Swinkels CM, et al (2013). Diagnostic efficiency of the AUDIT-C in U.S. veterans with military service since September 11, 2001. Drug Alcohol Depend, 132, 101-6.

Dawson DA, Grant BF, Stinson FS, Zhou Y (2005). Effectiveness of the derived alcohol use disorders identification test (audit-c) in screening for alcohol use disorders and risk drinking in the US general population. Alcohol Clin Exp Res, 29, 844-54.

Dawson DA, Smith SM, Saha TD, Rubinsky AD, Grant BF (2012). Comparative performance of the AUDIT-C in screening for DSM-IV and DSM-5 alcohol use disorders. Drug Alcohol Depend, 126, 384-8.

de Menezes RF, Bergmann A, Thuler LC (2013). Alcohol consumption and risk of cancer: a systematic literature review. Asian Pac J Cancer Prev, 14, 4965-72.

Frank D, DeBenedetti AF, Volk RJ, et al (2008). Effectiveness of the AUDIT-C as a screening test for alcohol misuse in three race/ethnic groups. Gen Intern Med, 23, 781-7.

Gómez A, Conde A, Santana JM, et al (2006). The diagnostic usefulness of AUDIT and AUDIT-C for detecting hazardous drinkers in the elderly. Aging Ment Health, 10, 558-61.

Johnson JA, Lee A, Vinson D, Seale JP (2013). Use of AUDITbased measures to identify unhealthy alcohol use and alcohol dependence in primary care: a validation study. Alcohol Clin Exp Res, 37, 253-9.

Kaarne T, Aalto M, Koukkanen M, Seppa K (2010). AUDIT-C, AUDIT-3 and AUDIT-QF in screening risky drinking among Finnish occupational health-care patients. Drug Alcohol Rev, 29, 563-7.

Kelly TM, Dnovan JE, Chung T, Bukstein OG, Cornelius JR (2009). Brief screens for detecting alcohol use disorder among 18-20 year old young adults inn emergency departments: comparing AUDIT-C, CRAFFT, RAPS4-QF, FAST, RUFT-Cut, and DSM-IV 2-item scale. Addict Behav, 34, 668-74.

Nordqvist C, Johansson K, Bendtsen P (2004). Routine screening for risky alcohol consumption at an emergency department using the AUDIT-C questionnaire. Drug Alcohol Depend, 74, 71-5.

Osaki Y, Matsushita S, Shirasaka T, Hiro H, Higuchi S (2005). Nationwide survey of alcohol drinking and alcoholism among Japanese adults. Nihon Arukoru Yakubutsu Igakkai Zasshi, 40, 455-70.

Osaki Y, Higuchi S, Matsushita S, Kishimoto T (2012). Social costs of alcohol misuse in Japan. Japanese Journal of Hygiene, 67, 320.

Osaki Y (2013). Trends in drinking behavior and alcoholrelated disorders in Japan. Progress I Medicine, 33, 803-7. Rodriguez-Martos A, Santamarina E (2007). Does the short form of the Alcohol Use Disorders Identification Test (AUDIT-C) work at a trauma emergency department? Subst Use Misuse, 42, 923-32.

Towers A, Stephens C, Dulin P, et al (2011). Estimating older hazardous and binge drinking prevalence using AUDIT-C and AUDIT-3 thresholds specific to older adults. Drug Alcohol Depend, 117, 211-218.

Tuunanen M, Aalto M, Seppa K (2007). Binge drinking and its detection among middle-aged men using AUDIT, AUDIT-C and AUDIT-3. Drug Alcohol Rev, 26, 295-299.

WHO (2009). Global health risks: mortality and burden of disease attributable to selected major risks. World Health Organization, Geneva.

Yaegashi Y, Onoda T, Morioka S, et al (2014). Joint effects of smoking and alcohol drinking on esophageal cancer mortality in Japanese men: findings from the Japan collaborative cohort study. Asian Pac J Cancer Prev, 15, 1023-9.

Youden WJ (1950). Index for rating diagnostic tests. Cancer, 3, 32-5. 